\title{
Identificação de Polímeros
}

M. ${ }^{\text {a }}$ do Rosário Marvão * C.M.A. Ribeiro **
Mostre-se a uma especialista um pedaço de um plástico qualquer e pergunte-se-lhe: o que é isto? A resposta, se a houver, será provavelmente confidencial, por deferência pessoal.

Explicando melhor: considere-se um pedaço de um material que, por não ser visivelmente metálico, cerâmico ou de outra natureza facilmente reconhecível, se admite ser polimérico. A questão agora é saber qual o polimero que constitui a base de tal material. Acontece que as propriedades directamente apreciadas pelos nossos sentidos poderão ser neste caso enganadoras. A cor, pode ser condicionada por corantes; o cheiro, só raramente será característico; a rigidez, poderá ter sido modificada por plastificantes. E para a elasticidade, uma enorme gama de valores pode ser tecnicamente realizável, até para um mesmo polímero.

E no entanto a identificação de polímeros é um dado essencial na actividade economica. É fundamental para a defesa do consumidor, para a defesa da indústria geral de uma geração cujo modo de vida está já indissoluvelmente ligado aos materiais poliméricos e suas propriedades específicas.

\section{Processos Simples de Identificação}

Existe uma dúzia de polimeros cujas propriedades e cujos preços lhes permitem cobrir a quase totalidade do consumo nacional. É tentador olhar para eles e verificar as suas diferenças. Será uma primeira abordagem, valerá como um palpite.

Num quadro junto listam-se os polímeros mais comuns e esquematizam-se as características mais acessiveis (Quadro I). As designaçð̄es correntes são o meio de comunicação coloquial. O consumo dá ideia da abundância relativa e portanto de probabilidade de encontro casual. A resistência à chama e as características de combustão são a cartilha de quem não tem um labora-

QUADRO I

\begin{tabular}{|c|c|c|c|c|c|c|c|c|c|}
\hline \multirow[b]{2}{*}{ POL IMEROS } & \multirow{2}{*}{$\begin{array}{l}\text { DESIGNAÇÃO } \\
\text { COMERCIAL. }\end{array}$} & \multirow{2}{*}{$\begin{array}{l}\text { PRODUÇĀ̃o } \\
\text { NACIONAL } \\
\text { (Ton/ano) }\end{array}$} & \multirow[b]{2}{*}{$\begin{array}{r}\text { IMPORTAÇÃo } \\
\text { (Ton/ano) }\end{array}$} & \multicolumn{2}{|c|}{ RESISTENCIA A CHAMA } & \multicolumn{2}{|c|}{ CARACTERISTICAS DA COMBUSTAO } & \multirow[b]{2}{*}{ SOLUBILIDADE } & \multirow[b]{2}{*}{ ESTRUTURA QUTMICA } \\
\hline & & & & $\begin{array}{l}\text { ARDE E NAO } \\
\text { SE EXTIINGUE }\end{array}$ & \begin{tabular}{|l|} 
ARDE MAS \\
EXTINGUE-SE
\end{tabular} & COR DA CHAMA & ODOR DOS. FUMOS & & \\
\hline $\begin{array}{l}\text { Poli(etileno) de baixa } \\
\text { densidade }\end{array}$ & PEBD & 120000 & - & $x$ & & $\begin{array}{l}\text { amarela com } \\
\text { base azul }\end{array}$ & cêra,estearina & $\begin{array}{l}\text { Hidrocarbonetos } \\
\text { a quente }\end{array}$ & $+\mathrm{CH}_{2} \mathrm{CH}_{2}+$ \\
\hline $\begin{array}{l}\text { Polif(etileno) de alta } \\
\text { densidade }\end{array}$ & PEAD & 60000 & - & $x$ & & $\begin{array}{l}\text { amarela com } \\
\text { base azul }\end{array}$ & cêra, estearina & $\begin{array}{l}\text { Hidrocarbonetos } \\
\text { a quente }\end{array}$ & $+\mathrm{CH}_{2} \mathrm{CH}_{2}+$ \\
\hline Poll(propileno) & PP & 50000 & - & $x$ & & $\begin{array}{l}\text { amarela com } \\
\text { base azul }\end{array}$ & cêra, estearina & $\begin{array}{l}\text { Hidrocarbonetos } \\
\text { aromáticos e } \\
\text { clorados a alta } \\
\text { temperatura }\end{array}$ & $+\mathrm{CH}_{2}-\underset{1}{\mathrm{CH}+}+\underset{\mathrm{CH}_{3}}{\mathrm{CH}}$ \\
\hline Polli(cloreto de vinilo) & PVC & 60000 & - & & $x$ & $\begin{array}{l}\text { amarela com } \\
\text { base verde }\end{array}$ & $\begin{array}{l}\text { fumos ácidos e } \\
\text { picantes }\end{array}$ & $\begin{array}{l}\text { Oimetil formami- } \\
\text { da, tetra-hidro } \\
\text { furano, ciclo- } \\
\text {-hexanona }\end{array}$ & $+\mathrm{CH}_{2}-\underset{1}{\mathrm{CH}}+$ \\
\hline Poll(estireno) & PS & - & 14000 & $x$ & 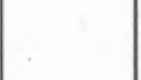 & $\begin{array}{l}\text { amarela com } \\
\text { base azui e } \\
\text { muitos fumos }\end{array}$ & estireno & $\begin{array}{l}\text { Hidrocarbonetos } \\
\text { aromáticos e } \\
\text { clorados }\end{array}$ & $+\mathrm{CH}_{2}$ \\
\hline $\begin{array}{l}\text { Terpolimero de acrilo- } \\
\text { nitrilo-butadieno-estif } \\
\text { reno }\end{array}$ & ABS & - & 3500 & $x$ & & $\begin{array}{l}\text { amarela com } \\
\text { base azul e } \\
\text { muitos fumos }\end{array}$ & estireno & $\begin{array}{l}\text { Cloreto de } \\
\text { metileno }\end{array}$ & \\
\hline $\begin{array}{l}\text { Poli(metacrilato de } \\
\text { met110) }\end{array}$ & PMMA & - & 4000 & $x$ & & $\begin{array}{l}\text { amarela com } \\
\text { base azul }\end{array}$ & frutas & $\begin{array}{l}\text { Hidrocarbonetos } \\
\text { aromáticos e } \\
\text { clorados, éste-- } \\
\text { res e cetonas }\end{array}$ & $+\mathrm{CH}_{2}-{\underset{\mathrm{COOCH}}{3}}_{\mathrm{C}}^{\mathrm{C}}+$ \\
\hline Poli(acrilonitrilo) & PAN & 26000 & - & $x$ & & $\begin{array}{l}\text { amarela lumi- } \\
\text { nosa }\end{array}$ & $\underset{\mathrm{da}}{\mathrm{madei}}$ & $\begin{array}{l}\text { Dimetil formami- } \\
\text { da, nitrofenol. }\end{array}$ & 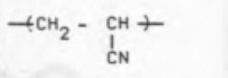 \\
\hline $\begin{array}{l}\text { Resina Je Ureía - } \\
\text {-formaldeido } \\
\text { rectículada }\end{array}$ & uF & 120000 & & & $x$ & $\begin{array}{l}\text { amarela pá1i- } \\
\text { da com contor } \\
\text { no azul-esve } \bar{r} \\
\text { deado }\end{array}$ & $\begin{array}{l}\text { formaldeído e } \\
\text { semelhante a } \\
\text { peixe }\end{array}$ & $\begin{array}{l}\text { Benzil amina( } 16000 \\
\text { amónia }\end{array}$ & $+\underset{\substack{\mathrm{C} \\
\mathrm{H}_{2}}}{\mathrm{~N}-\mathrm{CO}-\mathrm{N}-\mathrm{CH}_{2}+}$ \\
\hline
\end{tabular}

nacional e para a salvaguarda da colecta fiscal. Mas também se tornou num dado imprescindivel na cultura
* Departamento de Tecnologia de Indústrias Químicas - LNETI

** Departamento de Química da Faculdade de Ciências de Lisboa. 
QUADRO I (cont.)

\begin{tabular}{|c|c|c|c|c|c|c|c|c|c|}
\hline \multirow[b]{2}{*}{ POL IMEROS } & \multirow{2}{*}{\begin{tabular}{|c|} 
DESIGNAÇAOA \\
COMERCIAL
\end{tabular}} & \multirow{2}{*}{$\begin{array}{l}\text { PRODUÇAO } \\
\text { NACIONAL } \\
\text { (Ton/ano) }\end{array}$} & \multirow[b]{2}{*}{$\begin{array}{c}\text { IMPORTAÇAO } \\
\text { (Ton/ano) }\end{array}$} & \multicolumn{2}{|c|}{ RESISTENCIA A CHAMA' } & \multicolumn{2}{|c|}{ CARACTERISTICAS DA COMBUSTAOO } & \multirow[b]{2}{*}{ SOLUBILIDADE } & \multirow[b]{2}{*}{ ESTRUTURA QUIMICA } \\
\hline & & & & $\begin{array}{l}\text { ARDE E NAO } \\
\text { SE EXIINGUE } \\
\end{array}$ & \begin{tabular}{|l|} 
ARDE MAS \\
EXTINGUE-SE \\
\end{tabular} & COR DA CHAMA & ODOR DOS FUMOS & & \\
\hline $\begin{array}{l}\text { Resina de Melamina - } \\
\text { formaldeido recticu- } \\
\text { lada }\end{array}$ & MF & & - & & $x$ & $\begin{array}{l}\text { amarela pál1- } \\
\text { da com contor } \\
\text { no azul esver } \\
\text { deado }\end{array}$ & \begin{tabular}{l|} 
formaldeido e \\
peixe queimado
\end{tabular} & \begin{tabular}{|l} 
Benzilamina \\
$(1600 \mathrm{C})$ \\
amón1a
\end{tabular} & \\
\hline Polif(uretano) & Pu & 12000 & - & $x$ & & $\begin{array}{l}\text { amarela com } \\
\text { base azul }\end{array}$ & picante & $\begin{array}{l}\text { Tetra-nidrofu- } \\
\text { rano, dimetil- } \\
\text { formamida, fci } \\
\text { do fórmico }\end{array}$ & $-0+$ \\
\hline Poli(éster) & - & 5000 & - & $x$ & & $\begin{array}{l}\text { amarela com } \\
\text { base azul e } \\
\text { multos fumos }\end{array}$ & estireno & $\begin{array}{l}\text { insolúveis quan } \\
\text { do curadas }\end{array}$ & $+\underset{0}{\text { OROCA' }}]_{0}^{-}+$ \\
\hline $\begin{array}{l}\text { poli(isopreno) } \\
\text { [borracha natural] }\end{array}$ & NR & - & 12000 & $x$ & & $\begin{array}{l}\text { amarela } \\
\text { muit tos fumos } \\
\text { mos }\end{array}$ & $\begin{array}{l}\text { borracha que1- } \\
\text { mada }\end{array}$ & $\begin{array}{l}\text { insolúvel quan } \\
\text { do vulcanizadâa }\end{array}$ & $\mathrm{CH}=\mathrm{CH}_{2}+$ \\
\hline $\begin{array}{l}\begin{array}{l}\text { Poll (butadieno co-est } 1 \\
\text { reno) }\end{array} \\
\text { a }\end{array}$ & SBR & - & 15000 & $x$ & & $\begin{array}{l}\text { amarela com } \\
\text { muitos fumos }\end{array}$ & estireno & $\begin{array}{l}\text { insolúvel quan } \\
\text { do vulcanizada }\end{array}$ & \\
\hline Polí(butadieno) & eR & - & 5000 & $x$ & & $\begin{array}{l}\text { amarela com } \\
\text { base azul e } \\
\text { multos funos }\end{array}$ & $\begin{array}{l}\text { fraco, adocica } \\
\text { do }\end{array}$ & $\begin{array}{l}\text { insolúvel quan } \\
\text { do vulcanizadâ }\end{array}$ & $+\mathrm{CH}=\mathrm{CH}_{-}-\mathrm{CH}_{2}-\mathrm{OH}_{2}+$ \\
\hline $\begin{array}{l}\text { Polí(butadieno co- } \\
\text {-acrilonitrilo) } \\
\text { [Borracha nitrilica] }\end{array}$ & NBR & - & 5000 & $x$ & & $\begin{array}{l}\text { amarela } \\
\text { muitos fum } \\
\text { mumos }\end{array}$ & $\begin{array}{l}\text { fraco, adocica } \\
\text { do }\end{array}$ & $\begin{array}{l}\text { insolúvel quan } \\
\text { do vulcanizadâ }\end{array}$ & $\mathrm{HOH}_{2}$ \\
\hline
\end{tabular}

tório. A solubilidade é útil num laboratório pouco sofisticado.

Convém ainda acrescentar as principais utilizaçōes desta dúzia de polímeros, porque, para cada utilização existe normalmente um polimero que se apresenta como mais apropriado. Uma judiciosa consulta do Quadro II pode constituir uma pista rápida de identificação, embora de modo algum segura.

\section{Processos Sofisticados de Identificação}

Se se reparar na estrutura química dos polímeros de maior consumo (Quadro I), verifica-se existirem diferenças estruturais que podem ser utilizadas para a sua identificação. Um método clássico consiste em obter-se um espectro de absorção no infra-vermelho e da sua análise inferir-se da presença desta ou daquela singularidade estrutural. Ao longo dos anos acumularam-se dados espectroscópicos sobre centenas de polímeros estando já hoje compilados em diversas publicaçōes (1). A obtenção de um espectro de absorção no I.V. exige a preparação prévia de um filme, pastilha ou solução apropriados, o que se nalguns casos pode ser imediata, normalmente, requer extensa manipulação da amostra e consideráveis conhecimentos técnicos. Uma das dificuldades mais frequentes resulta da amostra ser compósita, isto é, conter para além do polímero, aditivos tais como corantes, cargas minerais, plastificantes, estabilizantes, anti-oxidantes, etc. Nestes casos podem ser necessárias extracções múltiplas com solventes específicos para remoção dos aditivos interferentes. Outra dificuldae, de ainda mais problemática solução, surge quando o polímero a identificar não é solúvel em nenhum solvente. Usam-se, nestes casos, técnicas tais como moagem a temperaturas inferiores à temperatura de transição vítrea do polímero (p. ex. $-70{ }^{\circ} \mathrm{C}$ para poli(isopreno)). Todas estas manipulaçð̃es e muitas outras encontram-se convenientemente descritas $(2,3)$, recomendando-se a sua consulta no caso de utilização deste método.

Outros métodos poderiam aqui ser invocados, mas de facto em termos práticos, cada qual por sua razão tem um campo de aplicação bastante restrito.

Devido a estas dificuldades e à necessidade de as ultrapassar tem vindo a desenvolver-se um outro método o de pirólise com cromatografia em fase gasosa - . Na pirólise os polímeros são termicamente degradados, obtendo-se produtos voláteis cuja composição depende da natureza do polímero e das condiçōes de pirólise. A identificação e possivel quantificação dos produtos de pirólise é efectuada por cromatografia em fase gasosa. Para que este método analítico seja simples e eficiente, a amostra a analisar é pirolisada na zona de injecção do cromatógrafo, sendo os produtos voláteis obtidos arrastados para a coluna onde são separados e posteriormente detectados. Os pirogramas obtidos, transformados em pirogramas relativos ao de um padrão (p. ex. PEAD), permitem obter valores reprodutíveis dos tempos de retenção dos diferentes picos característicos e conduzir a uma clara identificação dos principais produtos de decomposição pirolítica de um dado tipo de polímero. Da comparação de pirogramas relativos de amostras de vários materiais conclui-se que, de um modo geral, eles são suficientemente distintos para permitir uma identificação definitiva do tipo de polímero constituinte. Entre as vantagens desta técnica conta-se a de não ser necessária a preparação prévia da amostra, podendo portanto utilizar-se o produto na sua forma original, além das quantidades de material a analisar serem mínimas (inferiores a $1 \mathrm{mg}$ ).

Identificar é classificar, é procurar relaçð̄es de similitude, de parentesco. Dentro de uma mesma família podem contudo descernir-se diversas características. Um 
Quadro II

\begin{tabular}{|c|c|}
\hline Aplicações & $\begin{array}{l}\text { Tipos de polímeros } \\
\text { mais utilizados }\end{array}$ \\
\hline Fibras sintéticas & $\begin{array}{l}\text { PAN, PP, Poli(éster) } \\
\text { linear, PA }\end{array}$ \\
\hline Filmes para embalagem e para estufas & PEBD, PEAD, PP \\
\hline $\begin{array}{l}\text { Tubos e tubagens para águas e } \\
\text { revestimento de cabos eléctricos }\end{array}$ & PEAD, PVC \\
\hline Cordoaria, ráfias, suportes de alcatifas & PP \\
\hline $\begin{array}{l}\text { Embalagens para produtos alimentares, } \\
\text { farmacêuticos, de cosmética e } \\
\text { industrais }\end{array}$ & $\begin{array}{l}\text { PEBD, PEAD, PVC } \\
\text { PS }\end{array}$ \\
\hline Tampas, cápsulas, grades para garrafas & PEAD, PP \\
\hline Isolamentos térmicos & $\begin{array}{l}\text { PS, PU (espuma } \\
\text { rigida) }\end{array}$ \\
\hline $\begin{array}{l}\text { Napas, revestimentos vinilicos, } \\
\text { alguns componentes de calçado }\end{array}$ & PVC \\
\hline $\begin{array}{l}\text { Brinquedos, caixas de rádio, tele- } \\
\text { visão e computadores, cassettes, inte- } \\
\text { riores de frigorificos }\end{array}$ & PS \\
\hline $\begin{array}{l}\text { Componentes para a indústria auto- } \\
\text { móvel }\end{array}$ & PP, ABS, PU \\
\hline $\begin{array}{l}\text { Estruturas de barcos, caixas de car- } \\
\text { ruagens, pranchas de surf, grandes } \\
\text { reservatorios, contentores }\end{array}$ & $\begin{array}{l}\text { Poli(éster) reforçados } \\
\text { com fibra de vidro }\end{array}$ \\
\hline Vidro acrilico & PMMA \\
\hline $\begin{array}{l}\text { Laminados decorativos, elementos } \\
\text { para cozinhas }\end{array}$ & $\begin{array}{l}\text { Resinas de ureia-for- } \\
\text { maldeído ou de } \\
\text { melamina-formal- } \\
\text { deído recticuladas }\end{array}$ \\
\hline Pneus & NR, SBR \\
\hline O'rings & $\begin{array}{l}\text { NBR, Silicone, Fluo- } \\
\text { relastómero }\end{array}$ \\
\hline $\begin{array}{l}\text { Tubos, tubagens hidráulicas e de } \\
\text { alta pressão }\end{array}$ & CR, NBR, EPDM \\
\hline Suportes anti-vibração e anti-choque & NR \\
\hline $\begin{array}{l}\text { Solas de sapatos, revestimentos de } \\
\text { pavimento }\end{array}$ & NR \\
\hline Cintas transportadoras & NBR, CR \\
\hline Adesivos & NBR, BR, SBR \\
\hline
\end{tabular}

sistema polimérico identifica-se pela sua natureza química, como se acabou de mostrar, mas caracteriza-se pelas suas propriedades físicas e pela sua topologia molecular.

\section{BIBLIOGRAFIA}

(1) Hummel, D.O., Scholl, F., "Atlas of Polymer and Plastics Analysis". Verlag Chemie. 1981.

(2) Haslam, J., "Idenfication and Analysis of Plastics". London, Heyden, 1981.

(3) Miller, R.G.J., Stace, B.C., "Laboratory Methods in Infrared Spectroscopy". London, Heydem \& Son Lda., 1979. 